\title{
A Remotely Operated Vehicle Scaffolded Activity is Increasing Student and Teacher Interest in STEM - a Reporting on a Three-year Study Funded by the Office of Naval Research
}

\section{Dr. Geoff Wright, Brigham Young University}

Dr. Geoffrey A. Wright is an associate professor of Technology and Engineering Education in the Ira A. Fulton College of Engineering and Technology.

\section{Mr. Randy Craig Hurd, Brigham Young University}

I am currently a PhD candidate at Brigham Young University. My research is focused around the fluid dynamics associated with the oblique free surface of highly deformable spheres. I have conducted research on urinal splash dynamics, which simplifies to droplet impacts into thin liquid films. This work was featured by the BBC and Wired magazine. I also work as a volunteer administrator for an ROV outreach program in central Utah known as Utah Underwater Robotics and study the affect of this program on student interest in STEM education.

\section{Kip Schafer Hacking, Brigham Young University \\ Prof. Tadd T Truscott, Brigham Young University}

Tadd Truscott's current research interests are in fluid dynamics, novel imaging and experimental methods. By merging different areas of research, he works on problems such as three-dimensional flow field dynamics of rising spheres and cavitation. Tadd received his B.S in mechanical engineering from the University of Utah, and then attended Massachusetts Institute of Technology for Ph.D. in Ocean and Mechanical Engineering. He is presently an assistant professor at Brigham Young University, but will join the faculty at Utah State University in 2015. 


\section{A Remotely Operated Vehicle (ROV) Scaffolded Activity is Increasing Student and Teacher Interest in STEM - a Reporting on a Three-year Study Funded by the Office of Naval Research}

\section{Introduction}

For the past three years a university in the western United States has worked to build a scaffolded STEM program, using curriculum from STEM content areas and embedding it into an ROV building activity. The curriculum and activity require students to learn various basic STEM principles including buoyancy, pressure, density, circuits, and the engineering design process, while designing, building, testing, and competing with a personally-built ROV. The data in this paper discusses the results from the implementation this past year with over 400 students. The data results from a pre post STEM survey. The survey was administered prior to the students participating in the activity, and immediately following the final ROV competition ( $\sim 5$ month delay). The data shows some initial positive trends of student $(n=437)$ interest in math, science, engineering, and technology increasing, along with their proficiency in problem solving methods. We believe this is a reflection of embedding STEM principles in an exciting, hands-on activity. This paper outlines the three-year effort, discussing the ROV activity, associated curriculum taught, and also presents the measurement tools used to aggregate the student and teacher data points and associated results.

\section{Background}

For the last decade there has been a general call to promote interest and competency in STEM education. This called has echoed from various sources ranging from the President of the United States [1] and the Department of Defense [2] to independent companies [3] concerned with fulfilling future workforce demands. The concern rises from the abundance of STEM-related employment, a lack of qualified individuals to fill those positions, and the fact that STEM technologies and production play an invaluable role in national and global economies, [4][5].

For the reasons mentioned above, significant funding, time, and resources, have been invested in the United States with the intent of sparking STEM interest among young citizens. For example, in STEM outreach, there is a myriad of programs and activities just within the field of robotics and automation. Examples of these type of programs include: FIRST, LEGO Mindstorms, VEX Robotics, MATE, SeaPerch, OpenROV, etc.

Robotics is often chosen as a method to teach a broader version of STEM because it provides an educational medium students find both interesting and exciting [6]. From a STEM perspective, robotics are also quite diverse, meaning students must generally learn about topics from various branches of STEM in order to build a successful robot. In fact all four subjects (science, technology, engineering, and mathematics) play a critical role [7], for example in many Lego Mindstorm applications math is used in the programming to calculate angles to move the robots, and various principles of science are used for understanding thrust, velocity, amplitude, acceleration, and much more), making robotics valuable beyond their initial shelf appeal. Additionally, robotics programs have also proven to be effective in peaking student interest in STEM topics [8]. Because of their positive reception and apparent effectiveness, similar programs are being used all over the nation in various capacities to increase STEM interest, and appear to be effective. Not only do these programs seem effective at motivating students, but also appear to be carrying enough appeal and valor to additionally motivate both teachers and parents to support interested students.

\section{Methods}


A collaborative group from BYU, incorporating professors from mechanical engineering, education, technology and engineering education, and electrical engineering, directed the ROV outreach program. The implementation of the ROV activity and associated curriculum, however, was implemented at a smaller level though local teachers and after-school group leaders. The program consisted of three primary phases: (1) teacher training, (2) teachers returning and teaching their students, and (3) end of year ROV competition. The teachers were trained at the beginning of the year in what an ROV was, how to build one (i.e., solder circuit boards, wire and water proof motors, etc.). They were also taught the engineering design process (EDP), and provided lesson plan material for the EDP, circuitry, buoyancy, ballasts, and water pressure and density. Teachers were then asked to take the material and teach it however they wanted, while having the students build their ROVs (the implementation of the instruction varied, depending on if the ROV program was implemented as an after school program/club, or if the teacher used in as part of their science or math curriculum). The final phase involved the students competing against 400 other students in an end of year ROV competition at a local pool.

Though initially constructed as a logistics meeting, the preliminary training meetings with teachers has become one of the most valuable aspects of this ROV outreach program. First and foremost these meetings function as an informative training to educate teachers about program specifics, demonstrate effective STEM teaching activities and finally to educate teachers about specific principles and techniques essential. The primary training consisted of a presentation on program logistics to make sure teachers are familiar with the program structure, final competition tasks, important dates, etc. Teachers were also presented with some activities and teaching aids that effectively teach some of the important but often more difficult STEM concepts associated with the program. A subsequent meeting focused on skills such as soldering, wiring, circuitry and tuning vehicle buoyancy. This essentially gave the teachers an opportunity to do all of the difficult steps themselves before teaching to their students. From this standpoint the program was quite unified, and we feel this helps keep programs in the same ballpark so to speak. Conversely, teachers were encouraged to try knew things are run their classes and programs in a way they felt was most effective, which spawned a great amount of creativity and growth within the program. While the program was primarily designed to increase student interest in STEM topics, it seems that the program in general and especially the teacher training was had a significant influence on teacher efficacy in relation to STEM subjects, more particularly engineering and technology.

Individual teachers conveyed the curriculum and ROV activity to the students with diverse approaches and in various settings. The most popular was in an after school type programming with teachers from the school providing instruction and supervision while building. However, other after-school programs depended completely on parent or community volunteers, while other groups run by teachers were done completely in-class and merged into the existing curriculum. Some groups discussed the project several days a week, where other groups met for long periods of time once a week. Students typically worked building robots in groups of three. Participant ages ranged from 11-15, with participants typically coming from grades 6-9. Individual groups attracted volunteers from a variety of sources including BYU's student volunteer organization, the BYU college of engineering and technology and from parents. Some groups provided a significant amount of teaching integrating with ROV construction, while many focused primarily on the building activity. Groups typically started construction in October and completed their ROVs in early March.

The final competition was held in early March at a local indoor community pool. The event was meant to serve a variety of purposes: first to provide an opportunity for students to see how their ROV would perform in a real situation, second to further educate students about the academic and career opportunities that exist within STEM, and finally to provide a reward for the student's hard work. Each competing group was 
given a specific time to try and complete a set of underwater tasks. Students were given points for completing tasks as well as a possible time bonus. Additionally competing teams were required to present a poster outlining their ROV design, which also contributed to their final score. In addition to the competitive events, various local STEM companies and university labs set up booths at the competition to engage the students and inform them about the many future possibilities in STEM. The event was charged with a positive energy and seemed to get all involved excited about STEM as a whole.

\section{Findings}

The findings are a result of a data aggregation collected from a pre and post survey that was administered prior to the participants engaging in the ROV activity and curriculum, and immediately following their participation in the end of year ROV competition. The survey was based on a modified version of the TESS (Teaching Engineering Self-Efficacy Scale). Although the researchers believe the survey could be improved, and will further work on the survey over the course of this next year to do so, because the initial implementation of the ROV competition did not have a research focus or agenda, the survey was not of primary concern. However, with the rapid growth and popularity of the ROV effort within the state (in regards to competition participants, and educational stake holder support) the researchers believe there is a need to aggregate and analyze data pertinent to activity and curriculum. Consequently, that is why the researchers decided to use the TESS that related studies have suggested as providing some reliability and validity. Graph 1.1 documents the relative growth of this effort based on the ROV competition participants. Note that year 3 of the competition now includes two locations - one in the northern part of the state, and the other in the southern part of the state. This was in direct result of the competitions popularity among schools, community, and the various educational stakeholders.

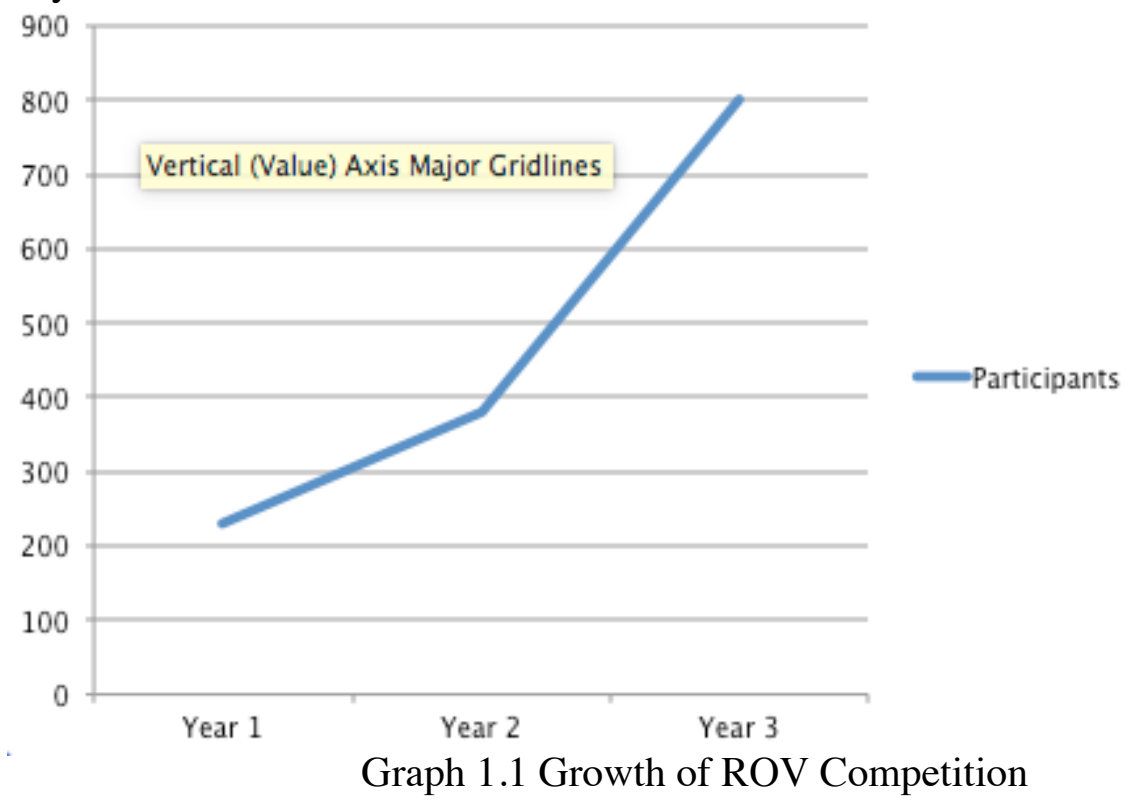

The data in table 1.1 which outlines both some of the questions from the survey, and also the pre and post mean scores, in addition to some basic descriptive statistics highlight two important findings. First, the statistics are not statistically significant. Second, despite the level of significance, the data does show increase in all but 1 category. This positive trend could suggest that the increase is due to random variation, or it could suggest that if measured over a longer period of time, that statistical significance may arise. Regardless, the researchers believe that in light of the increase in each of the questions (except one) that the trend is important to consider. Certainly considering the 
random variation of how the ROV and curriculum may have been implemented. The researchers believe the trend does suggest that a difference can and is being made, and although not statistically significant, perhaps with additional support or teacher training, and improved curriculum (i.e., train teachers on how to better incorporate the stem principles into their classrooms and lesson, move the programs from after school efforts to during school efforts) that the trend may increase towards statistical significance. Graphs 1.2 and 1.3 show the positive increases. The researchers also believe that the popularity and overwhelming support of the ROV competition is a qualitative data point that adds credence to their claim that this ROV effort is a worthy cause - and could prove to make a positive statistical significance with further adoption, development, and study.

\begin{tabular}{|l|r|r|l|l|}
\hline Questions & Pre & Post & \multicolumn{2}{l|}{ for 95\% CI= 1.9 } \\
\hline $\begin{array}{l}\text { An engineer is someone } \\
\text { who uses science to build } \\
\text { new and useful things }\end{array}$ & 4.22 & 4.47 & $\begin{array}{l}\mathrm{sd}=0.3102 ; \\
\mathrm{se}=0.018\end{array}$ & $\begin{array}{l}\text { df-t: } 274.5 ; \\
\mathrm{p}=0.32639\end{array}$ \\
\hline $\begin{array}{l}\text { Engineering improves our } \\
\text { lives }\end{array}$ & 4.27 & 4.32 & $\begin{array}{l}\mathrm{sd}=0.3097 ; \\
\mathrm{se}=0.0185\end{array}$ & $\begin{array}{l}\mathrm{df}-\mathrm{t}: 278.5 ; \\
\mathrm{p}=0.35298\end{array}$ \\
\hline $\begin{array}{l}\text { I like to find out how things } \\
\text { work }\end{array}$ & 4.03 & 4.06 & $\begin{array}{l}\mathrm{sd}=0.3009 ; \\
\mathrm{se}=0.018\end{array}$ & $\begin{array}{l}\mathrm{df}-\mathrm{t}: 278.9 ; \\
\mathrm{p}=0.3593\end{array}$ \\
\hline $\begin{array}{l}\text { I would like to be an } \\
\text { engineer someday }\end{array}$ & 2.8 & 3.03 & $\begin{array}{l}\mathrm{sd}=0.2546 ; \\
\mathrm{se}=0.0154\end{array}$ & $\begin{array}{l}\mathrm{df}-\mathrm{t}: 272.6 ; \\
\mathrm{p}=0.34861\end{array}$ \\
\hline $\begin{array}{l}\text { I would like to take a class } \\
\text { about engineering }\end{array}$ & 3.21 & 3.5 & $\begin{array}{l}\mathrm{sd}=0.2725 ; \\
\mathrm{se}=0.0165\end{array}$ & $\begin{array}{l}\mathrm{df}-\mathrm{t}: 272 ; \mathrm{p}= \\
0.3346\end{array}$ \\
\hline $\begin{array}{l}\text { I am good at building things } \\
\text { I am very creative }\end{array}$ & 3.48 & 3.55 & $\begin{array}{l}\mathrm{sd}=0.2806 ; \\
\mathrm{se}=0.0168\end{array}$ & $\begin{array}{l}\mathrm{df}-\mathrm{t}: 277.7 ; \\
\mathrm{p}=0.36274\end{array}$ \\
\hline I am good at science & 4.1 & 4 & $\begin{array}{l}\mathrm{sd}=0.3019 ; \\
\mathrm{se}=0.018\end{array}$ & $\begin{array}{l}\mathrm{df}-\mathrm{t}: 281.5 ; \\
\mathrm{p}=0.37644\end{array}$ \\
\hline $\begin{array}{l}\text { I am good at math } \\
\text { I }\end{array}$ & 3.59 & 3.8 & $\begin{array}{l}\mathrm{sd}=0.2865 ; \\
\mathrm{se}=0.0173\end{array}$ & $\begin{array}{l}\mathrm{df}-\mathrm{t}: 274.6 ; \\
\mathrm{p}=0.341\end{array}$ \\
\hline $\begin{array}{l}\text { I am good at using } \\
\text { technology }\end{array}$ & 3.68 & 3.8 & $\begin{array}{l}\mathrm{sd}=0.2889 ; \\
\mathrm{se}=0.0174\end{array}$ & $\begin{array}{l}\mathrm{df}-\mathrm{t}: 276.7 ; \\
\mathrm{p}=0.35213\end{array}$ \\
\hline
\end{tabular}

Table 1.1. Pre and Post Mean Scores with Descriptive Statistical Data

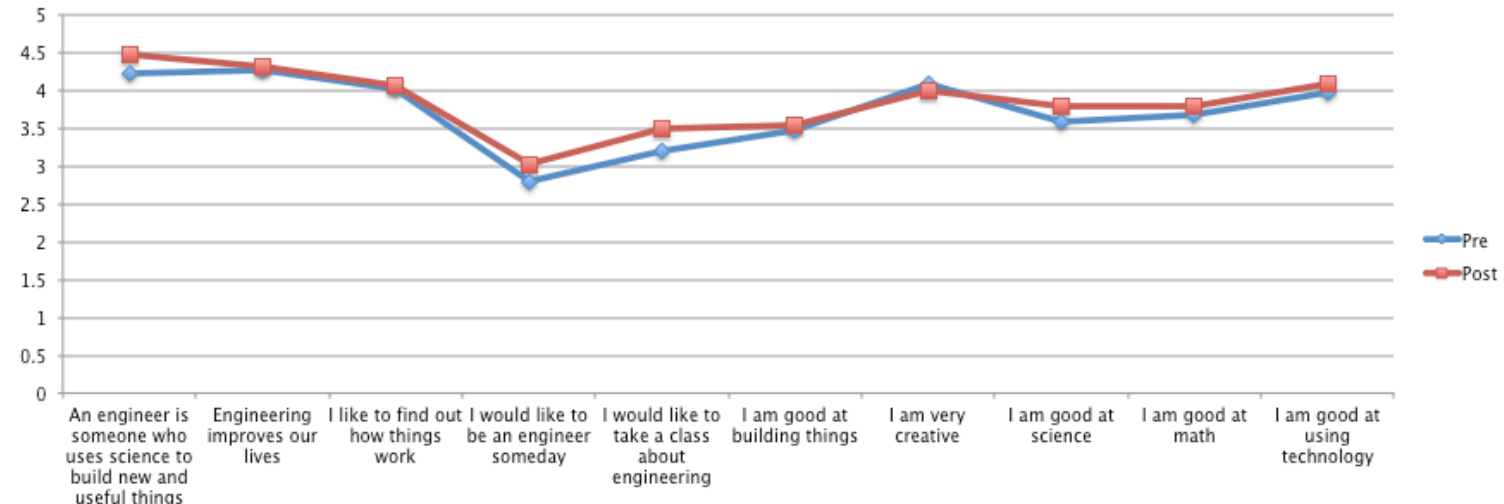

Graph 1.2: Line Graph Showing Pre and Post Scores 


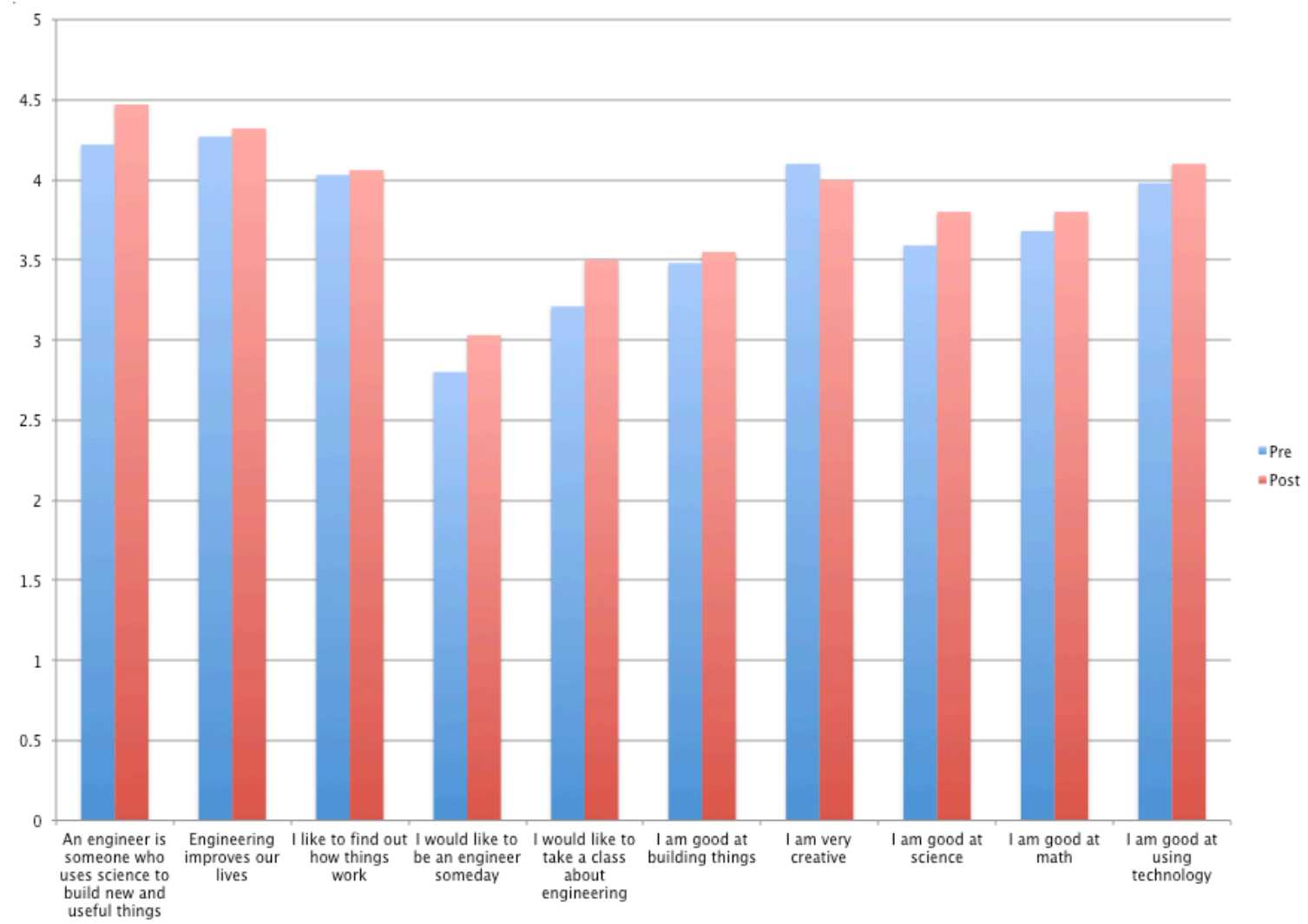

Graph 1.3: Bar Graph Showing Pre and Post Scores

\section{Conclusions}

The four primary outcomes of this project are: (1) student interest and abilities in STEM areas are increasing in result of this ROV program. Although not yet statistically significant, the positive increase over the three-year implementation suggests a positive trend. (2) Education stakeholders (students, parents, teachers, administrators, and community members) are fully engaged and supportive of this type of STEM ROV activity. They all intuitively believe this type of program, where curriculum is embedded in a hands-on building pedagogy, coupled with STEM curriculum activities and lessons, will help students have a good experience with STEM disciplines and content, which may influence them to study and work in those fields, or a at minimum be more STEM literate. An example of the belief in this program is not just in its exponential growth (regarding school and participant population) over the past three years, but also comes from the state's STEM Action Center and various state agencies and companies who have donated time and resources to helping this program become sustainable. For example, although the program was first funded through a grant received from the Office of Naval Research, the program has now received sufficient funding from the state, and several local/state-wide agencies to run the program without additional help. (3) In light of the positive statistical trend, anecdotal supportive evidence, and qualitative observations made by the researchers, from interviews and fields notes, ROV based STEM outreach programs designed in a similar method work, meaning they will expose and teach students STEM principles. Although we have yet to see if early interventions such as this will have a long lasting impact, we believe they will, because when students are exposed to excited and engaging educational experiences at early ages [9], they will demand similar experiences in future courses and grade levels, thus perpetuating this cause through their educational careers. (4) The final outcome we learned from this project is that STEM programs will not work if they are perceived as additional work for 
teachers and schools. For example in our ROV program, we noticed that teachers were invested because they were either really great teachers and cared a great deal about STEM and their students, or they were hired as after school coordinators. That is not to say those teachers who did not participate are not excellent teachers who care, but rather, they are busy, and they only select extra things (such as this effort) if it fits their area of interest, skill set, or bandwidth (time and resources). Consequently, we intuitive believe (based on our field notes from interviews with teachers and administrators) that if a program like this is to most effectively work - meaning, if it is to make a more significant academic influence on students, it would have to be part of the regular school day core curriculum. This will not happen unless standards change to include more engineering and technology. STEM exists at schools as SXXM, where engineering and technology are not perceived as core course offerings in most states. They instead are typically offered as electives. Unless schools and states adopt the entire STEM discipline as core and essential, outreach and after school programs will remain the only alternative to teach students about STEM in a blended curriculum. We will continue our ROV effort, training in-service teachers about ROV and associated STEM curriculum, however, we make a call to university pre-service teacher programs to train their teachers how to teach STEM as a blended curriculum, where each content area influences and can be leveraged to understand and explore the other disciplines. Additional we suggest educational stakeholders pursue opportunities to continue the evolution of state and national educational outcomes towards fully adopted STEM standards. This is imperative because of society's dependency on the STEM areas and diminishing STEM working; if students are going to be marketable, and help make our economy be competitive and sustainable in the future, they need training in STEM.

\section{References}

[1] OBAMA, BARACK, (2012). State of the union address. whitehouse.gov

[2] Funding Opportunity Announcement for Navy and Marine Corps Science, Technology, Engineering \& Mathematics Education, Outreach and Workforce Program. 2014 ONR-FOA-15-0002. onr.navy.mil

[3] GORDON, CHRISTINA, (2014). Corporate CEOs reach 330,000 young people through high-quality STEM programs, will reach 1 million by the end of 2016. changetheequation.org

[4] ROTHWELL, JONATHAN, (2013). The hidden STEM economy: Key findings. brookings.edu

[5] CASEY, BOB, (2012). STEM education: Preparing for the jobs of the future. US Congress Joint Economic Committee.

[6] VERNER , I.M. \& AHLGREN, D.J., (2004) Robot Contest as a Laboratory for Experiential Engineering Education. Journal on Educational Resources in Computing, $4(2), 1-15$

[7] FABIANE B., \& VAVASSORI B., (2012). Exploring the educational potential of robotics in schools: A systematic review. Computers \& Education, 58(3), 978-988

[8] MELCHIOR, A., COHEN, F., CUTTER, T. \& LEAVITT, T., (2005). More than robots: An evaluation of the FIRST robotics competition participants and institutional impacts. Center for Youth and Communities, Brandeis University. 
[9] BERK, L \& WINSLER, A., (1995). "Vygotsky: His life and works" and "Vygotsky's approach to development". In Scaffolding children's learning: Vygotsky and early childhood learning. Natl. Assoc for Educ. Of Young Children. p. 24 